\title{
Angka kejadian apendisitis di RSUP Prof. Dr. R. D. Kandou Manado periode Oktober 2012 - September 2015
}

\author{
${ }^{1}$ Gloria A. Thomas \\ ${ }^{2}$ Ishak Lahunduitan \\ ${ }^{2}$ Adrian Tangkilisan
}

\author{
${ }^{1}$ Kandidat Skripsi Fakultas Kedokteran Universitas Sam Ratulangi Manado \\ ${ }^{2}$ Bagian Ilmu Bedah Fakultas Kedokteran Universitas Sam Ratulangi Manado \\ Email: gloriathomas94@yahoo.com
}

\begin{abstract}
Appendicitis is an inflammation of vermiform appendix. Acute inflammation of the appendix needs to be treated immediately to prevent fatal complications. The incidence among females and males is slightly comparable, however, the incidence is higher among males than females in the age range between 20-30 years. The fundamental clinical decision in the diagnosis of a patient with suspected appendicitis is whether to do an operation or not. The meaningful evaluation of acute appendicitis balances early operative intervention to prevent operative risks. This study aimed to obtain the incidence of appendicitis at Prof. Dr. R.D Kandou Hosiptal Manado from October 2012 to September 2015. This was a retrospective descriptive study using data of the Department of Medical Record Prof. Dr. R.D Kandou Manado Hospital. The results showed that there were 650 patients. Most patients had acute appendicitis as many as 412 patients (63\%) meanwhile chronic appendicitis was found in 38 patients (6\%). Of 650 patients, 200 patients had complications; 193 patients (30\%) with perforated appendicitis and 7 patients (1\%) with appendicular mass. The most frequent age group to develop appendicitis was 20-29 years. The number of male patients was higher than the females.
\end{abstract}

Keywords: appendicitis, incidence

\begin{abstract}
Abstrak: Apendisitis adalah adanya peradangan pada apendiks vermiformis. Peradangan akut pada apendiks memerlukan tindak bedah segera untuk mencegah komplikasi yang umumnya berbahaya. Insidens pada perempuan dan laki-laki umumnya sebanding, kecuali pada umur 20-30 tahun insidens pada laki-laki lebih tinggi. Keputusan klinis mendasar dalam mendiagnosis pasien dengan dugaan apendisitis ialah apakah perlu dilakukannya operasi atau tidak. Evaluasi yang baik dari kasus apendisitis akut dapat mengurangi intervensi untuk operasi awal, dengan harapan dapat mengurangi risiko operasi yang tidak diperlukan. Penelitian ini bertujuan untuk mengetahui angka kejadian apendisitis di RSUP Prof. Dr. R. D, Kandou Manado periode Oktober 2012 - September 2015. Metode penelitian yang digunakan ialah deskriptif retrospektif dengan menggunakan data di Bagian Rekam Medik RSUP Prof. Dr. R. D. Kandou Manado. Hasil penelitian menunjukkan bahwa selama periode Oktober 2012 - September 2015 terdapat 650 pasien. Jumlah pasien terbanyak ialah apendisitis akut yaitu 412 pasien (63\%) sedangkan apendisitis kronik sebanyak 38 pasien (6\%). Dari 650 pasien, yang mengalami komplikasi sebanyak 200 pasien yang terdiri dari 193 pasien (30\%) dengan komplikasi apendisitis perforasi dan 7 pasien (1\%) dengan periapendikuler infiltrat. Kelompok umur tersering yang menderita apendisitis ialah 20-29 tahun. Jumlah pasien laki-laki lebih banyak daripada perempuan.
\end{abstract}

Kata kunci: apendisitis, angka kejadian

Apendiks atau yang lebih dikenal masyarakat dengan istilah usus buntu, adalah salah satu organ visceral pada sistem gastrointestinal yang sering menimbulkan masalah kesehatan. ${ }^{1}$ Adanya peradangan pada apendiks vermiformis disebut dengan apendisitis. ${ }^{2}$ Peradangan akut pada apendiks memerlukan tindak 
bedah segera untuk mencegah komplikasi yang umumnya berbahaya. Peradangan pada apendiks merupakan kausa laparotomi tersering pada anak dan orang dewasa. ${ }^{3}$

Apendisitis dapat ditemukan pada semua umur, hanya pada anak kurang dari satu tahun jarang dilaporkan karena apendiks pada bayi berbentuk kerucut, lebar pada pangkalnya dan menyempit kearah ujungnya. Keadaan ini menyebabkan rendahnya insidens kasus apendisitis pada usia tersebut. ${ }^{1}$ Setiap tahun rata-rata 300.000 orang menjalani apendektomi di Amerika Serikat, dengan perkiraan lifetime incidence berkisar dari 7-14\% berdasarkan jenis kelamin, harapan hidup dan ketepatan konfirmasi diagnosis. ${ }^{4}$ Perforasi lebih sering pada bayi dan pasien lanjut usia, yaitu dengan periode angka kematian paling tinggi. ${ }^{5}$ Insidens pada perempuan dan laki-laki umumnya sebanding, kecuali pada umur 20-30 tahun, ketika insidens pada laki-laki lebih tinggi. ${ }^{1}$

Dalam bentuk tanda dan gejala fisik, apendisitis adalah suatu penyakit prototipe yang berlanjut melalui peradangan, obstruksi dan iskemia dalam jangka waktu yang bervariasi. ${ }^{6}$ Gejala awal apendisitis akut adalah nyeri atau rasa tidak enak di sekitar umbilikus. Gejala ini umumnya berlangsung lebih dari 1 atau 2 hari. Dalam beberapa jam nyeri bergeser ke kuadran kanan bawah dengan disertai oleh anoreksia, mual dan muntah. Dapat juga terjadi nyeri tekan disekitar titik Mc Burney. Kemudian timbul spasme otot dan nyeri tekan lepas. Apabila terjadi ruptur pada apendiks, tanda perforasi dapat berupa nyeri, nyeri tekan dan spasme. ${ }^{7}$

Diagnosis apendisitis sedikit menantang. Gejala klinis sering atipikal dan diagnosis apendisitis cukup sulit karena gejalanya yang tumpang tindih dengan kondisi lain. Keputusan klinis mendasar dalam mendiagnosis pasien dengan dugaan apendisitis ialah apakah perlu dilakukannya operasi atau tidak. Evaluasi yang baik dari apendisitis akut dapat mengurangi intervensi untuk operasi awal, dengan harapan dapat mengurangi risiko operasi yang tidak diperlukan. ${ }^{8}$
Menurut The Lancet perkembangan mortalitas apendisitis terlihat dimana pada tahun 1990 tingkat mortalitas pada keseluruhan umur adalah sebanyak 875.000 kematian sedangkan pada tahun 2013 mengalami penurunan menjadi 719.000 kematian. $^{9}$ Secara nasional, perkembangan penyakit ini belum mendapat perhatian yang serius. Hal ini ditunjukkan lewat minimnya data tentang penyakit ini. Demikian halnya dengan data di tingkat lokal Sulawesi Utara, yaitu di RSUP Prof. R.D Kandou Manado.

Penelitian ini bertujuan yuntuk mendapatkan angka kejadian pasien apendisitis yang dirawat di Bagian Bedah RSUP Prof. Dr. R.D Kandou Manado periode Oktober 2012 - September 2015.

\section{METODE PENELITIAN}

Penelitian ini bersifat deskriptif retrospektif dengan menggunakan data rekam medik (data sekunder) pasien apendisitis di RSUP Prof. Dr. R. D. Kandou Manado. Penelitian ini dilakukan di Bagian Rekam Medik RSUP Prof. Dr. R. D. Kandou Manado. Variabel penelitian ialah jumlah kasus, umur, jenis kelamin, dan komplikasi. Subjek penelitian ialah semua pasien apendisitis di RSUP Prof. Dr. R. D. Kandou Manado periode Oktober 2012 - September 2015, terbukti telah dilakukan apendektomi dan tercatat dalam laporan operasi.

\section{HASIL PENELITIAN}

Berdasarkan penelitian secara deskriptif retrospektif di Bagian Rekam Medik RSUP Prof. Dr. R. D. Kandou Manado pada periode Oktober 2012 - September 2015 didapatkan 650 pasien apendisitis.

Tabel 1 memperlihatkan bahwa jumlah kasus apendisitis yang paling banyak ialah apendisitis akut sebanyak 412 kasus (63\%), diikuti oleh apendisitis perforasi sebanyak 193 kasus (30\%), dan apendisitis kronik sebanyak 38 kasus (6\%). Kasus yang paling sedikit ialah peripendikuler infilrat yang hanya ditemukan sebanyak 7 kasus (1\%). Dari 650 kasus, hanya 31\% yang mengalami komplikasi. 
Tabel 1. Distribusi pasien Apendisitis

\begin{tabular}{ccc}
\hline Diagnosa & Jumlah & $\%$ \\
\hline Apendisitis akut & 412 & 63 \\
Apendisitis kronik & 38 & 6 \\
Apendisitis perforasi & 193 & 30 \\
Periapendikuler & 7 & 1 \\
infiltrat & & \\
Total & 650 & 100 \\
\hline
\end{tabular}

Berdasarkan hasil penelitian yang diperoleh, kelompok umur 0-9 tahun terdapat 43 pasien (7\%), kelompok umur 10-19 tahun terdapat 164 pasien (25\%), kelompok umur 20-29 tahun terdapat 224 pasien (34\%), kelompok umur 30-39 tahun terdapat 66 pasien (10\%), kelompok umur 40-49 tahun terdapat 56 pasien (9\%), kelompok umur 50-59 tahun terdapat 52 pasien (8\%), dan kelompok umur $>60$ tahun terdapat 45 pasien (7\%).

Tabel 2. Distribusi pasien apendisitis berdasarkan kelompok umur

\begin{tabular}{ccc}
\hline $\begin{array}{c}\text { Kelompok umur } \\
\text { (Tahun) }\end{array}$ & Jumlah & $\%$ \\
\hline $0-9$ & 43 & 7 \\
$10-19$ & 164 & 25 \\
$20-29$ & 224 & 34 \\
$30-39$ & 66 & 10 \\
$40-49$ & 56 & 9 \\
$50-59$ & 52 & 8 \\
$>60$ & 45 & 7 \\
\hline
\end{tabular}

Berdasarkan data yang diperoleh dapat dilihat bahwa dari 650 kasus, jenis kelamin laki-laki yang menderita apendisitis sebanyak 363 pasien (56\%), sedangkan perempuan sebanyak 287 pasien (44\%).

Tabel 3. Distribusi pasien apendisitis berdasarkan jenis kelamin

\begin{tabular}{ccc}
\hline Jenis Kelamin & Jumlah & $\mathbf{\%}$ \\
\hline Laki-laki & 363 & 56 \\
Perempuan & 287 & 44 \\
Total & 650 & 100 \\
\hline
\end{tabular}

Hasil penelitian menunjukkan bahwa pasien apendisitis pada kelompok umur 09 tahun terdapat 30 orang laki-laki dan 13 orang perempuan; pada kelompok umur
10-19 tahun terdapat 96 orang laki-laki dan 68 orang perempuan; pada kelompok umur 20-29 tahun terdapat 69 orang laki-laki dan 155 orang perempuan; pada kelompok umur 30-39 tahun terdapat 66 orang lakilaki dan tidak didapatkan pasien perempuan; pada kelompok umur 40-49 tahun terdapat 46 orang laki-laki dan 10 orang perempuan; pada kelompok umur 5059 terdapat 31 orang laki-laki dan 21 orang perempuan; dan pada kelompok umur $>60$ tahun terdapat 25 orang laki-laki dan 20 orang perempuan.

Berdasarkan data yang diperoleh dapat dilihat bahwa jenis kelamin laki-laki mendominasi dengan angka yang tinggi pada setiap kelompok umur kecuali pada kelompok umur 20-29 tahun dimana jenis kelamin perempuan memiliki jumlah yang lebih banyak daripada jenis kelamin lakilaki.

Tabel 4. Distribusi pasien Apendisitis berdasarkan kelompok umur dan jenis kelamin

\begin{tabular}{ccc}
\hline $\begin{array}{c}\text { Kelompok umur } \\
\text { (Tahun) }\end{array}$ & $\begin{array}{c}\text { Laki- } \\
\text { laki }\end{array}$ & Perempuan \\
\hline $0-9$ & 30 & 13 \\
$10-19$ & 96 & 68 \\
$20-29$ & 69 & 155 \\
$30-39$ & 66 & - \\
$40-49$ & 46 & 10 \\
$50-59$ & 31 & 21 \\
$>60$ & 25 & 20 \\
\hline
\end{tabular}

Tabel 5 menunjukkan bahwa pada kelompok umur 0-9 tahun terdapat 16 pasien apendisitis akut, 26 pasien apendisitis perforasi dan 1 pasien periapendikuler infiltrat. Pada kelompok umur 10-19 tahun terdapat 87 pasien apendisitis akut, 8 pasien apendisitis kronik dan 69 pasien apendisitis perforasi. Pada kelompok umur 20-29 tahun terdapat 191 pasien apendisitis akut, 3 pasien apendisitis kronik, 28 pasien apendisitis perforasi, dan 2 pasien periapendikuler infiltrat. Pada kelompok umur 30-39 tahun terdapat 37 pasien apendisitis akut, 8 pasien apendisitis kronik dan 21 pasien apendisitis perforasi. Pada kelompok umur 40-49 tahun terdapat 
31 pasien apendisitis akut, 9 pasien apendisitis kronik, 15 pasien apendisitis perforasi, dan 1 pasien periapendikuler infiltrat. Pada kelompok umur 50-59 tahun terdapat 30 pasien apendisitis akut, 4 pasien apendisitis kronik, 15 pasien apendisitis perforasi dan 3 pasien periapendikuler infiltrat. Pada kelompok umur $>60$ tahun terdapat 20 pasien apendisitis akut, 6 pasien apendisitis kronik dan 19 pasien apendisitis perforasi.

Tabel 5. Distribusi pasien Apendisitis berdasarkan kelompok umur dan diagnosa

\begin{tabular}{ccccc}
\hline $\begin{array}{c}\text { Kelompok umur } \\
\text { (Tahun) }\end{array}$ & $\begin{array}{c}\text { Apendisitis } \\
\text { akut }\end{array}$ & $\begin{array}{c}\text { Apendisitis } \\
\text { kronik }\end{array}$ & $\begin{array}{c}\text { Apendisitis } \\
\text { perforasi }\end{array}$ & $\begin{array}{c}\text { Periapendiku } \\
\text { ler infiltrat }\end{array}$ \\
\hline $0-9$ & 16 & - & 26 & 1 \\
$10-19$ & 87 & 8 & 69 & - \\
$20-29$ & 191 & 3 & 28 & 2 \\
$30-39$ & 37 & 8 & 21 & - \\
$40-49$ & 31 & 9 & 15 & 1 \\
$50-59$ & 30 & 4 & 15 & 3 \\
$>60$ & 20 & 6 & 19 & - \\
\hline
\end{tabular}

\section{BAHASAN}

Hasil penelitian di bagian Rekam Medik RSUP Prof. Dr. R.D Kandou Manado selama periode Oktober 2012 September 2015 menunjukkan bahwa jumlah pasien terbanyak ialah apendisitis akut yaitu sebanyak 412 pasien (63\%) sedangkan apendisitis kronik sebanyak 38 pasien (6\%). Dari 650 pasien, yang mengalami komplikasi adalah sebanyak 200 pasien yang terdiri dari 193 pasien (30\%) dengan komplikasi apendisitis perforasi dan 7 pasien (1\%) dengan periapendikuler infiltrat.

Jumlah kasus apendisitis akut lebih tinggi daripada apendisitis kronik, apendisitis perforasi dan periapendikuler infiltrat. Diagnosis apendisitis cukup menantang karena gejalanya yang sering tumpang tindih dengan kondisi lain, namun adanya tanda dan gejala yang khas membuat para klinisi dapat mendiagnosa lebih awal adanya apendisitis. Jumlah kasus apendisitis perforasi tergantung dari banyaknya kasus apendisitis akut karena apendisitis perforasi adalah komplikasi dari apendisitis akut yang tidak tertangani dengan cepat. Perforasi pada apendiks dipengaruhi oleh beberapa faktor seperti jangka waktu antara gejala dan penanganan, umur dan status imunitas. ${ }^{10}$ Adanya evaluasi yang bermakna serta intervensi operatif awal dapat mencegah komplikasi perforasi yang umumnya berbahaya. $^{11}$

Apendisitis kronik yang didapatkan dalam penelitian ini adalah sebesar $6 \%$ dari 657 pasien. Apendisitis kronik lebih jarang terjadi daripada apendisitis akut. Gejala yang dialami tidak jelas dan progresinya bersifat lambat. Di Amerika, insidens apendisitis kronik hanya sebesar 1\% diantara apendisitis yang lain. ${ }^{12}$

Distribusi pasien apendisitis berdasarkan kelompok umur menunjukkan bahwa kelompok umur yang paling banyak menderita apendisitis ialah kelompok umur 20-29 tahun yaitu sebanyak 224 pasien (34\%). Jumlah pasien yang paling sedikit ditemukan pada kelompok umur 0-9 tahun yaitu 43 pasien (7\%). Hal ini sesuai dengan penelitian yang dilakukan oleh Körner bahwa apendisitis jarang terjadi pada anakanak. $^{13}$ Diagnosa apendisitis pada anak sedikit sulit karena anak yang kurang komunikatif dan sukar untuk menentukan ada tidaknya rasa nyeri pada perut. Meskipun jarang ditemukan, namun harus tetap diawasi terutama pada anak-anak dengan riwayat nyeri kolik, muntah dan 
demam. $^{14,15}$

Kelompok umur 20-29 tahun memiliki persentase yang paling tinggi diantara kelompok umur yang lain yaitu sebesar 34\%. Penelitian sebelumnya yang dilakukan di Rumah Sakit Immanuel Bandung pada tahun 2013 ditemukan bahwa kelompok umur terbanyak yang menderita apendisitis ialah kelompok umur 26-35 tahun. ${ }^{12}$ Gearhart dan Silen $^{4}$ dalam bukunya mengatakan bahwa insidens puncak apendisitis akut ialah pada dekade kedua dan ketiga kehidupan. Hal ini sesuai dengan temuan bahwa insidens apendisitis tertinggi adalah pada umur 20-29 tahun.

Berdasarkan jenis kelamin dari 650 kasus, jenis kelamin laki-laki memiliki persentase sebesar $56 \%$, sedangkan jenis kelamin perempuan hanya sebesar $44 \%$. Ahmad $^{10}$ dalam penelitiannya menemukan bahwa insidens pada laki-laki lebih tinggi dibandingkan dengan perempuan. Inflamasi pada apendiks lebih umum ditemukan pada laki-laki, diduga karena adanya perubahan anatomis. ${ }^{16}$

Berdasarkan kelompok umur dan jenis kelamin, jenis kelamin laki-laki mendominasi pada setiap kelompok umur disbandingkan dengan jenis kelamin perempuan, kecuali pada kelompok umur 20-29 tahun dimana jenis kelamin perempuan lebih banyak daripada jenis kelamin laki-laki. Dalam beberapa penelitian dikatakan bahwa pada orang dewasa angka kejadian Apendisitis 1,4 kali lebih banyak pada laki-laki dibanding perempuan. Adapula yang menjelaskan bahwa insidens tertinggi adalah pada kelompok umur 20-30 tahun dimana jenis kelamin laki-laki lebih mendominasi. ${ }^{1,12}$ Temuan penelitian ini berbeda dengan beberapa penelitian sebelumnya, khususnya pada kelompok umur 20-29 tahun dimana pada kelompok umur ini dari 224 pasien yang didiagnosis apendisitis terdapat 31\% jenis kelamin laki-laki (69 pasien) dan 69\% jenis kelamin perempuan (155 pasien).

Berdasarkan kelompok umur dan diagnosa, pada kelompok umur 0-9 tahun, apendisitis perforasi memiliki jumlah kasus yang lebih banyak dibandingkan dengan apendisitis akut. Insidens perforasi tinggi pada anak disebabkan karena dinding apendiks anak yang masih tipis, anak kurang komunikatif sehingga memperpanjang waktu diagnosis, dan proses perdindingan kurang sempurna akibat perforasi yang berlangsung cepat dan omentum anak belum berkembang. ${ }^{1}$ Pada kelompok umur 10-19 tahun insidens apendisitis akut lebih tinggi daripada apendisitis perforasi. Adanya perkembangan maksimal dari jaringan limfoid di masa remaja menjadi faktor meningkatnya insidens apendiks untuk tersumbat, sehingga sumbatan yang sedikit saja akan menyebabkan tekanan intraluminal yang tinggi. $^{16}$

Jumlah kasus apendisitis akut yang paling tinggi ditemukan pada kelompok umur 20-29 tahun (191 pasien). Hal ini sesuai dengan teori yang mengatakan bahwa insidens tertinggi adalah pada kelompok umur 20-30 tahun dan setelah itu menurun. Pada kelompok umur $>60$ tahun ditemukan bahwa apendisitis akut masih lebih banyak daripada apendisitis kronik, apendisitis perforasi, dan periapendikuler infiltrat. Meskipun angka komplikasi apendisitis perforasi tidak terlalu tinggi, namun harus dievaluasi resiko terjadinya perforasi. Insidens perforasi pada pasien di atas 60 tahun dilaporkan sekitar $60 \%$. Faktor yang mempengaruhi tingginya insidens perforasi pada orang tua adalah gejalanya yang samar, keterlambatan berobat, adanya perubahan anatomi apendiks berupa penyempitan lumen dan arteriosklerosis yang dapat menyebabkan gangguan aliran arteri dan vena ke apendiks. Dalam suatu penelitian dikatakan bahwa usia di atas 60 tahun sudah tidak didapatkan lagi jaringan limfoid pada apendiks, terdapat perubahan pada lapisan serosa yang kurang elastik dibanding dengan lapisan mukosa sehingga menyebabkan respon terhadap tekanan intraluminal berbeda dengan pasien yang lebih muda. Kemampuan peregangan akibat akumulasi sekret intraluminal yang kurang baik dapat berlanjut menjadi iskemia dan gangrene stadium awal. ${ }^{1,17}$ 


\section{SIMPULAN}

Berdasarkan hasil penelitian secara deskriptif retrospektif di bagian Rekam Medik RSUP Prof. Dr. R.D Kandou Manado selama periode Oktober 2012 September 2015 dapat disimpulkan:

1. Angka kejadian apendisitis di RSUP Prof. Dr. R.D Kandou Manado selama periode Oktober 2012 - September 2015 sebanyak 650 kasus, yang paling banyak ialah apendisitis akut dan yang paling sedikit ialah Periapendikuler infiltrat.

2. Kelompok umur yang paling banyak menderita apendisitis ialah kelompok umur 20-29 tahun dan yang paling sedikit ialah kelompok umur 0-9 tahun.

3. Pada kelompok umur 20-29 tahun yang paling banyak dijumpai ialah apendisitis akut dan yang paling sedikit ialah periapendikuler infiltrat.

4. Pada keseluruhan kelompok umur, jenis kelamin laki-laki lebih banyak menderita apendisitis daripada jenis kelamin perempuan kecuali pada kelompok umur 20-29.

\section{DAFTAR PUSTAKA}

1. Sjamsuhidajat R, De Jong W. Buku Ajar Ilmu Bedah (3rd ed). Jakarta: EGC, 2010; p. 755-60.

2. Dorland WAN. In: Mahode AA et al, penerjemah. Dorland's Illustrated Medical Dictionary (11th ed). Indonesia: Elsevier; 2007; p. 137.

3. Kartono D. Apendisitis akuta. In: Reksoprodjo S, editor. Kumpulan Kuliah Ilmu Bedah Bagian Ilmu Bedah FKUI. Jakarta: Binarupa Aksara, p.115.

4. Flum D. Acute Appendicitis Appendectomy or The "Antibiotics First” Strategy. N Eng J Med. 2015;372:1937.

5. Gearhart S, Silen W. In: Longo D, Fauci A, editors. Harrison Gastroenterologi \& Hepatologi. Jakarta: EGC, 2013; p. 202.
6. Sabiston C. Buku Ajar Bedah (1st ed). Jakarta: EGC, 1995; p. 495.

7. Price S, Wilson L. Patofisiologi Konsep Klinis Proses-Proses Penyakit (6th ed). Jakarta: EGC, 2012; p. 448.

8. Shogilev D, Duus N, Odom S, Shapiro N. Diagnosing Appendicitis: Evidence-Based Review of The Diagnostic Approach in 2014. Western Journal of Emergency Medicine. 2014;15:860.

9. Naghavi $M$, Wang $H$, Lozano $R$, Davis A, Liang X, Zhou M, et al. Global, Regional, and National Age-sex Specific All-cause and Cause-specific Mortality For 240 Causes of Death, 1990-2013: A Systematic Analysis for the Global Burden of Disease Study 2013. Lancet. 2015;385:136.

10. Ahmad T, Ali Z, Ali A, Anjum S. Perforated Appendix: Contributing Factors. JUMDC. 2010;1:14.

11. Snell R. Anatomi Klinik (6th ed). Jakarta; EGC, 2006; p. 230-1.

12. Dani, Calista P. Karakteristik Penderita Apendisitis Akut di Rumah Sakit Immanuel Bandung Periode 1 Januari 2013 - 30 Juni 2013 [Skripsi]. Bandung: Universitas Kristen Maranatha; 2013.

13. Korner H, Sondenaa $K$, Soreide J, et al. Incidence of Acute Nonperforated and Perforated Appendicitis: Agespecific and Sex-specific Analysis. World Journal of Surgery. 2010;21:315.

14. John J, Hanini S, Popoiu C. Acute Appendicitis in Infants And Toddlers: Rare But Challenging. Journal of Pediatric. 2009;12:38.

15. Mantu F. Bedah Anak (1st ed). Jakarta: EGC, 2010; p. 148.

16. Lee $\mathbf{J}$. The Influence of Sex and Age on Appendicitis in Children and Young Adults. [Thesis]. London: Social Medicine Research Unit London Hospital, 2009.

17. Garba S, Ahmed A. Appendicitis in the Elderly. Intechopen.2010;1:109. 